\title{
Author Correction: Metabolite signatures of diverse Camellia sinensis tea populations
}

\author{
Xiaomin Yu (D), Jiajing Xiao, Si Chen, Yuan Yu (D), Jianqiang Ma, Yuzhen Lin, Ruizi Li, Jun Lin, Zhijun Fu, \\ Qiongqiong Zhou, Qianlin Chao, Liang Chen (1), Zhenbiao Yang (1) \& Renyi Liu (1)
}

Correction to: Nature Communications https://doi.org/10.1038/s41467-020-19441-1, published online 04 November 2020.

The original version of this Article contained an error in the Acknowledgements, which incorrectly read 'This work was supported by the Fujian Agriculture and Forestry University (FAFU) Construction Project for Technological Innovation and Service System of Tea Industry Chain (K1520005A02) and other funds from FAFU to X.Y., Z.Y. and R.L.' The correct version states 'Y.Y.' in place of 'Z.Y.'. This has been corrected in both the PDF and HTML versions of the Article.

Published online: 17 March 2021

\begin{abstract}
(c) (i)
Open Access This article is licensed under a Creative Commons Attribution 4.0 International License, which permits use, sharing, adaptation, distribution and reproduction in any medium or format, as long as you give appropriate credit to the original author(s) and the source, provide a link to the Creative Commons license, and indicate if changes were made. The images or other third party material in this article are included in the article's Creative Commons license, unless indicated otherwise in a credit line to the material. If material is not included in the article's Creative Commons license and your intended use is not permitted by statutory regulation or exceeds the permitted use, you will need to obtain permission directly from the copyright holder. To view a copy of this license, visit http://creativecommons.org/licenses/by/4.0/.
\end{abstract}

(C) The Author(s) 2021 